\title{
Article
}

Doi 10.5943/sif/6/1/19

\section{Antifungal effects of Ocimum Kilimandscharicum oil on Aspergillus flavus Infecting Maize after Harvest}

\author{
Kaguchia SM1ㅗㄹ Birgen JK${ }^{1}$, Lang'at-Thoruwa $C^{2}$ and Akwa TE*3 \\ ${ }^{1}$ Department of Plant Sciences, Kenyatta University, Nairobi, Kenya \\ ${ }^{2}$ Department of Chemistry, Kenyatta University, Nairobi, Kenya \\ ${ }^{3}$ Department of Biochemistry, Microbiology and Biotechnology Kenyatta University, Nairobi, Kenya
}

Kaguchia SM, Birgen JK, Lang'at-Thoruwa C, Akwa TE 2021 - Antifungal effects of Ocimum Kilimandscharicum oil on Aspergillus flavus Infecting Maize after Harvest. Studies in Fungi 6(1), 288-298, Doi 10.5943/sif/6/1/19

\begin{abstract}
Maize is consumed throughout the year in Kenya. Storage facilities of Maize vary with the economic status of the producers. Poor resource producers are likely to have unsuitable storage facilities whose conditions may predispose stored maize to post-harvest fungal infections. The most frequently encountered fungus in stored maize is Aspergillus flavus which produces aflatoxins that causes teratogenic, carcinogenic, mutagenic and hepatotoxic problems. Fungicides are used to control post-harvest fungi, but these have health implications. Hence an alternative safe method is the use of plant-based products which have anti-fungal compounds. This study was therefore designed to evaluate growth inhibitory effects of Ocimum kilimandscharicum oil on Aspergillus flavus. The leaves were collected from the plants growing naturally in Ruiru in Kiambu County, and the leaves were air dried in a shed, and oil was extracted through hydro-distillation. A total of $80 \mathrm{~kg}$ of threshed stored maize collected from randomly selected farms in Murang'a County were used to isolate Aspergillus flavus. Fungal growth experiments were done on PDA amended with different concentrations of the oil. Significant $(\mathrm{p}<0.001)$ inhibition of fungal radial growth occurred at oil concentration of $3.33 \mathrm{ul} / \mathrm{ml}$. However, concentrations above $6.67 \mathrm{ul} / \mathrm{ml}$ totally inhibited the growth of the fungus. Similarly, significantly $(p<0.001)$ large zones of inhibition were observed in the highest concentration of $400 \mathrm{ul} / \mathrm{ml}$. From the results, it can be concluded that O. kilimandscharicum oil acts against Aspergillus flavus and is a potential source for developing an antifungal agent. It is recommended that the efficacy of this oil needs to be tested on other postharvest fungi.
\end{abstract}

Keywords - Aflatoxins - Kenya - Mycelia inhibition - post-harvest fungi - storage conditions

\section{Introduction}

Maize (Zea mays) is a food crop that is consumed throughout the year in Kenya. It is mainly grown in the country in small holder farms as a basic source of food. Besides, the crop is also used as raw materials for many industrial processes. Majority of the communities in Kenya use maize to make a dish called 'Ugali' which is widely consumed in the country and therefore considered to be a staple food. Furthermore, maize is regarded as a source of income by farmers in Kenya (Birgen et al. 2020)

Majority of the families in Kenya consume maize meal at least once a day. Thus, to ensure constant availability of the product it is necessarily for farmers to store their maize after harvest. 
The preservation of the quality of the maize over the storage period depends on the status of the storage facilities. Storage facilities vary with the economic status of the producers. The poor resource producers are likely to have unsuitable storage facilities whose conditions predispose stored maize to post-harvest fungal infections, while more endowed producers may not. Postharvest fungal infection on products leads to deterioration of both the quality and quantity of the products (Akwa et al. 2020). The most notable genera of the post-harvest fungi that infect maize and contaminate with mycotoxins are Aspergillus, Fusarium and Penicillium (Farrell \& O'Keefe 2007). The most frequently encountered fungus in stored maize is A. flavus which produces aflatoxins that cause teratogenic, carcinogenic, mutagenic and hepatotoxic health problems (Birgen et al. 2020).

Fungicides has been used in the control of post-harvest fungi in stored food products. However, adverse effects on human health following consumption food products treated with fungicides has been observed (Dubey et al. 2007, Kumar et al. 2007). Some of these fungicides irritate the skin, tear glands; and disrupt neuron microtubules. This necessitates the search for safer alternatives for example the use of plant products.

Hence this publication addresses the use essential oils from Ocimum kilimandscharicum plants as an alternative to fungicides for the post-harvest control of Aspergillus flavus which is predominant in stored maize. Findings from this study will provide an alternative in the control of post-harvest fungi in maize rather than the use of fungicides.

\section{Materials \& methods}

\section{Description of Study Site}

The study took place in Murang'a County located in Kenya. Murang'a County has a population of about 942,841 inhabitants spanning over an area of about 756 square kilometres (Mutahi 2010). Bordering this county to the North is Nyeri District, to the Southwest is Marang'a District, to the West is Nyandarua District and to the East is Kirinyaga District. This county experiences variations in rainfall. Long duration of rains is observed in the period March to May with rainfall ranging between $1400 \mathrm{~mm}$ to $1600 \mathrm{~mm}$. The shorter duration being observed from October to November experiences average rainfall less than $900 \mathrm{~mm}$. Maximum agricultural productivity is observed during the long periods of rains. Temperatures vary in this part of Kenya with respect to altitude. At high altitudes, temperatures become as low as $6^{\circ} \mathrm{C}$.

In Murang'a County, land is widely used for agricultural purposes with different crops being cultivated such as maize, coffee and tea. A proportion of about $70 \%$ of agricultural land is used for the cultivation of maize (Mutahi 2010).

\section{Collection of Maize samples}

Sampling of maize farms was performed in Kangema which is a sub county in Murang'a County. Agriculture is the major economic activity in Kangema, with most of the land being used for cultivation of food crops (Ndagi 2017). A total of eighty farms were sampled where maize had already been harvested and no synthetic chemicals had been initially dusted in the granaries, houses and other storage. One Kilogram of threshed maize sample were randomly collected from the stores in each of the eighty selected farms making a total of $80 \mathrm{~kg}$ that formed the bulk sample. The moisture contents of the sampled maize were reduced to $13 \%$ by sun drying. This moisture content was established with the help of an electronic moisture meter (Wile 55 type). The collected maize samples were then transported aseptically in polythene bags to the Kenyatta University Plant Science Laboratory for fungal isolation.

\section{Isolation of Aspergillus flavus from maize samples}

Initial surface sterilization (sterilization of maize kernel) was carried out on the maize samples using the Schulz et al. (1993) standard sterilization protocol. For the isolation of fungi from the maize, Potato Dextrose Agar (PDA) prepared following the protocol by Aryal et al. (2015) 
was used as the culture media. The sterilized maize grains were directly plated on the culture medium. The maize grains were arranged at equidistance $3.0 \mathrm{~cm}$ apart in the plates. Five grains were plated on each petri plate which was replicated four times. The plates were later sealed using parafilm and incubated at a temperature of $25^{\circ} \mathrm{C}$ for a period of 7 days to ensure maximum growth of fungi (Samson et al. 2010).

\section{Morphological identification of Aspergillus flavus from maize}

Each of the fungal colonies which emerged from the plated maize grains after the period of incubation were individually sub- cultured in freshly prepared PDA media in petri dishes to obtain pure cultures. The subcultures were kept in an incubator maintained at $25^{\circ} \mathrm{C}$ for 7 days. Cultures which were uniformly growing with respect to color, texture and pigmentation were considered as pure colonies. Pure colonies of the fungi were identified following the methods outlined by Klich (2002) which comprised of fungal growth patterns, mycelia coloration and the appearance of the vegetative and reproductive structures.

\section{Pathogenicity test of Aspergillus flavus on maize grains}

To determine whether the A. flavus infects maize grains, pathogenicity test as outlined by Nikolić et al. (2016) of the identified fungi was performed in vitro. The pathogenicity test of Aspergillus flavus on maize was determined by inoculating clean/healthy maize grains with spore suspension of the fungus. The spore suspension was obtained from the pure cultures growing on PDA in petri dishes after the 7 days period of incubation. The spore suspension was obtained by adding $5 \mathrm{ml}$ of sterile distilled water into the petri dishes containing the pure cultures. The petri dishes were gently agitated to bring the spores into the suspension. The spore suspension was then dispensed or poured into a universal bottle. The concentrations of the spores in the universal bottle were estimated by a haemocytometer count. The healthy maize was placed on moistened filter papers and inoculated with a drop of the spore suspension whose concentration was estimated to be $1 \times 10^{3}$ spores $/ \mathrm{ml}$. The plates were later sealed with parafilm and incubated at $27^{\circ} \mathrm{C}$ for a period of 7 days to verify the fungal activity. Other maize samples were treated with sterile water only (no spore inoculation) and also incubated for the same period of time. These served as controls. After the duration of incubation, the developed symptoms on the spore inoculated maize samples were compared to the symptoms of the natural infected maize control to confirm the pathogenicity of the fungal isolates.

\section{Ocimum kilimandscharium sample collection and oil extraction}

Ruiru, Kiambu County was the site of collection of the Ocimum kilimandscharium plant (Fig. 1). The leaves of the plants were taken from their wild population. The taxonomic identification of the plant was performed in the plant sciences herbarium in which voucher specimens were kept.

Prior to oil extraction, the collected $O$. kilimandscharium leaves were air dried by placing them under a well-ventilated shade. This was done over a period of 5 days. Essential oil extraction was then performed on the plant, following the method of hydro distillation as documented by Erkan et al. (2012). This was then followed by the extraction of the distillate which was performed by passing over a solution anhydrous sodium sulphate. Solvent removal was carried out with the use of a rotary evaporator. The collected oil was then stored in a refrigerator using air tight bottles.

\section{Antifungal assay of Ocimum kilimandscharicum on Aspergillus flavus}

The antifungal activity of Ocimum kilimandscharicum was carried out using agar dilution method and disc diffusion technique following the procedure done by Bansod \& Rai (2008).

\section{Antifungal Assay by Agar Dilution Method}

In the method involving agar dilution, amended PDA medium of different concentrations 
(3.33, 6.67, 13.33, 20 and 26.67) $\mu 1 / \mathrm{ml}$ were used. The different concentrations were prepared by incorporating separate volumes $(400,300,200,100$ and 50) $\mu 1$ of the essential oil extracts of Ocimum kilimandscharicum plant into $15 \mathrm{ml}$ of melted PDA. An aliquot of $20 \mathrm{ml}$ of each amended medium was dispensed aseptically into sterile petri plates. The centre of each of the plates were then inoculated with $6 \mathrm{~mm}$ mycelia disc taken at the periphery of Aspergillus flavus pure cultures. For each inoculated PDA plate four replications were made. The arrangements of the plates were performed in a completely randomized manner.

Control treatments comprised of plain PDA (not amended with oil extract) inoculated with $A$. flavus. The petri plates were then incubated at $27^{\circ} \mathrm{C}$. The diameter of the colonies was recorded at 2 days intervals $(1,3,5$ and 7$)$ spanning a period of 7 days. The growth inhibition was assessed by comparing the mean colony diameters of Aspergillus in the treatments to the controls.

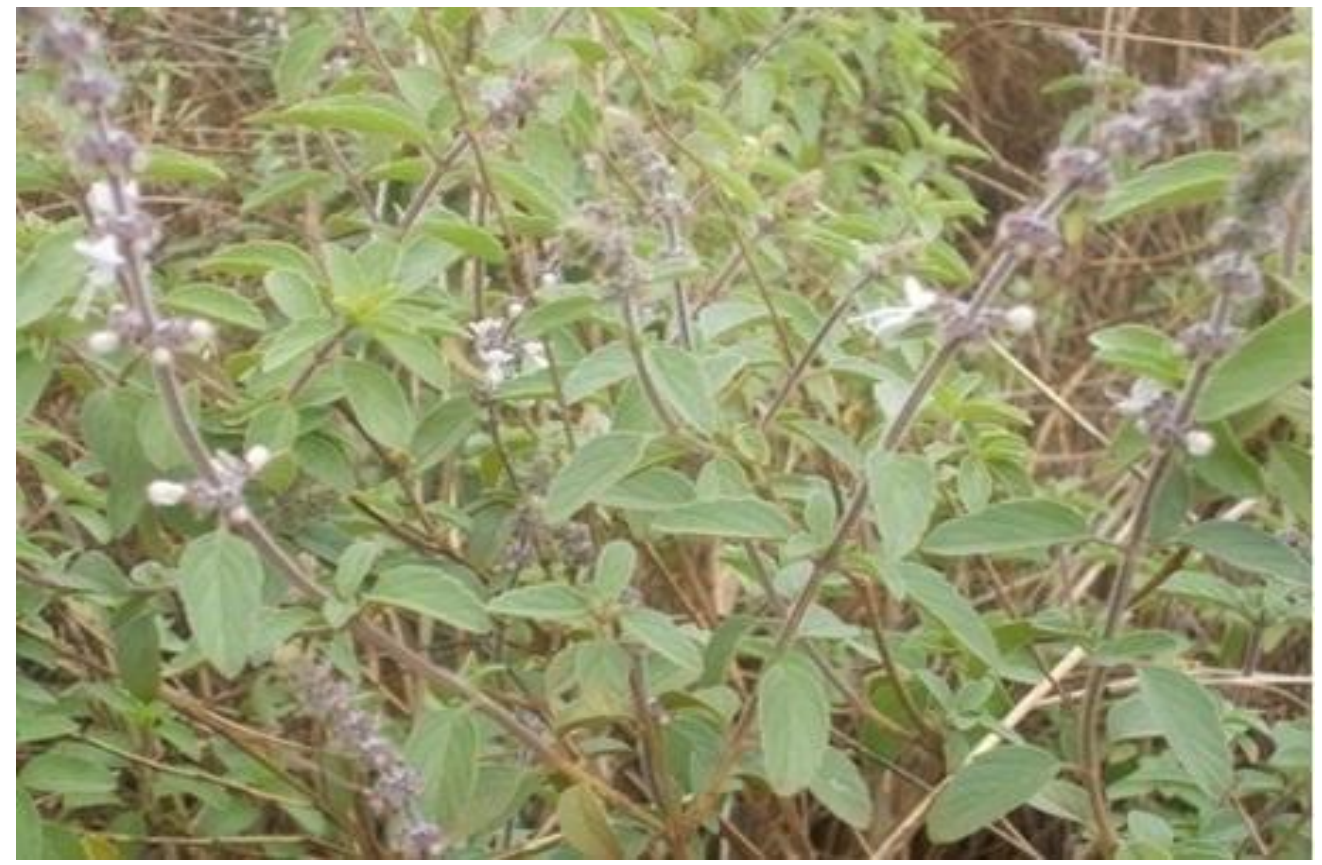

Fig. 1 - Ocimum kilimandscharium plants.

\section{Antifungal Assay by Disc Diffusion Technique}

In the disc diffusion method, filter paper disc of diameter $5 \mathrm{~mm}$ was cut and sterilized in an autoclave. Amended Ocimum kilimandscharicum of different concentrations (400, 300, 200, 100 and 50) $\mu \mathrm{l} / \mathrm{ml}$ were used. The different concentrations were prepared by diluting separate volumes $(400,300,200,100$ and 50) $\mu \mathrm{l}$ of the essential oil extracts of into $1 \mathrm{ml}$ of hexane. The sterilized paper disc was then immersed for 30 minutes in these concentrations. The paper disc was later removed from these concentrations, air dried and placed carefully on plates containing solidified PDA medium that had been amended with Aspergillus flavus spores suspension $\left(1 \times 10^{6}\right.$ spores $)$. For each of the plates four replications were made. The arrangements of the plates were performed in a completely randomized manner. The plates were then incubated at $27^{\circ} \mathrm{C}$. Control treatment comprised of sterile filter discs (not immersed in oil extracts) placed on PDA plates amended with A. flavus suspension. The size of the zone of inhibition were recorded at 2 days intervals $(1,3,5$ and 7) spanning a period of 7 days.

\section{Data analyses}

Data on radial growth inhibition were entered in a spread sheet, Microsoft Excel and normality determined. Transformation by $\log$ arithm, $\log 10(\mathrm{x}+1)$ was carried out followed by twoway ANOVA using SPSS Version 20 software. The means were separated using Tukey's HSD test at 0.05 level significance level. Tables and graphs were used in presenting the results. 


\section{Results}

\section{Identification of Aspergillus flavus from maize}

Macroscopically, the Aspergillus flavus colonies isolated from the maize grains showed rapid growth and appeared dark on upper side (surface) of the plate and creamy on its lower side (reverse). The texture was cottony and granular in appearance. Microscopically, the conidiophores were long, colourless and contained phialides. At the end of the conidiophore was borne globose conidia (Fig. 2).

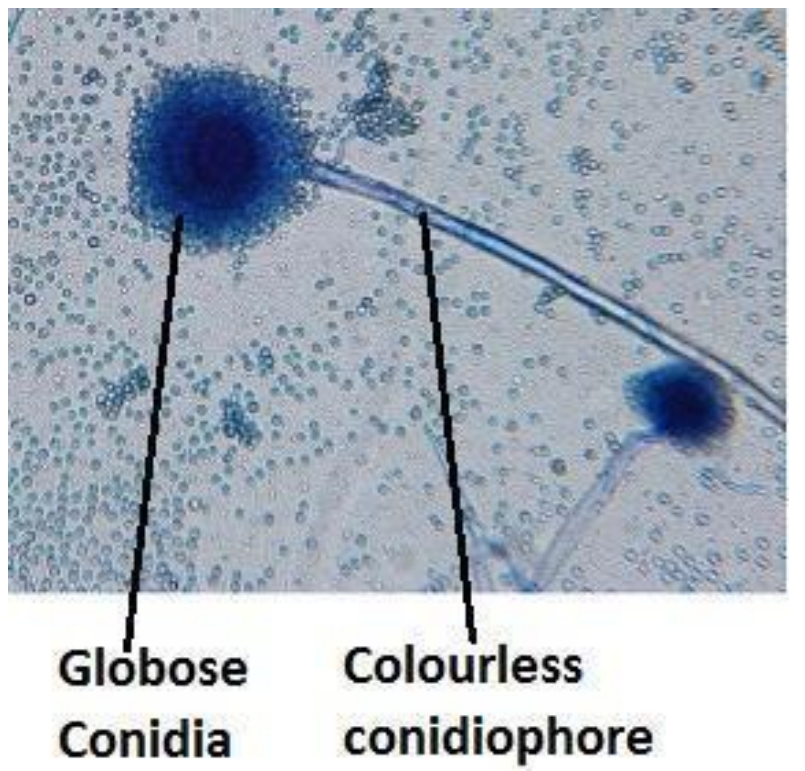

Fig. 2 - Microscopic view of Aspergillus flavus from maize grains ( $\times 40$ magnification).

\section{Pathogenicity test of Aspergillus flavus}

Maize inoculated with spore suspension of Aspergillus flavus started to rot after 4 days of incubation. The inoculated grains were totally consumed with extensive mycelial growth that formed dark coloration over the testa of the grains (Fig. 3). Comparison of the symptoms that emerged from the inoculated kernels to those of the control (no spore inoculation) confirmed the pathogenicity of the A. flavus isolates on the grains.

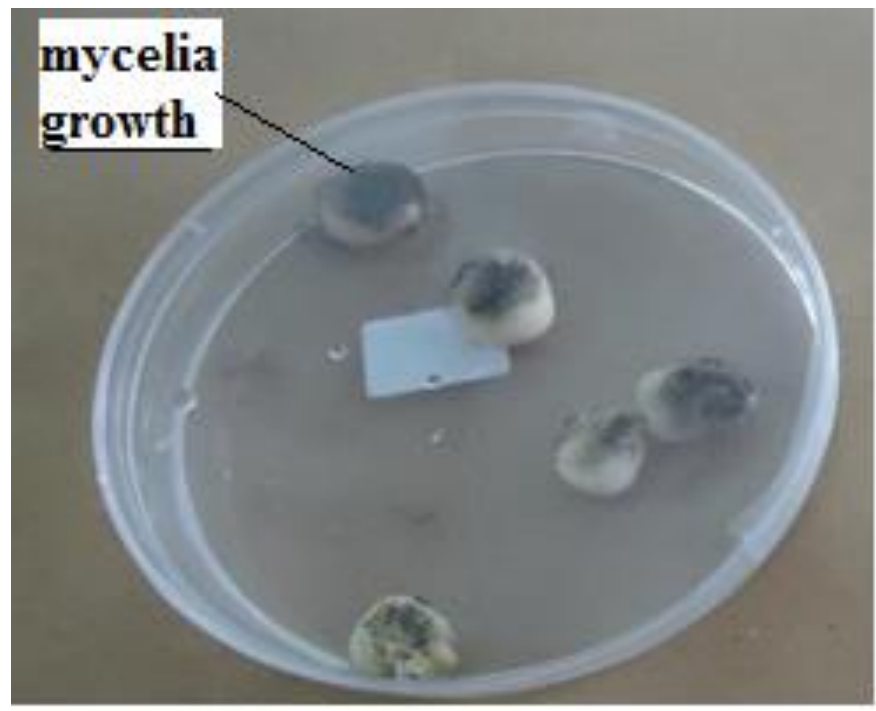

Fig. 3 - Pathogenicity test of Aspergillus flavus on maize grains. 


\section{Antifungal activity of Ocimum kilimandscharicum oil on Aspergillus flavus by Agar dilution method}

Results showed that the Ocimum kilimandscharicum oil inhibited the radial growth of Aspergillus flavus. The magnitude of the growth inhibition of the oil varied with its concentrations. Radial growth inhibition was $100 \%$ (no further growth of $A$. flavus occurred) at high concentrations $(26.67,20,13.33$, and 6.67) $\mu \mathrm{l} / \mathrm{ml}$. In the control experiment (plain PDA), a rapid growth of Aspergillus flavus was observed (Fig. 4).

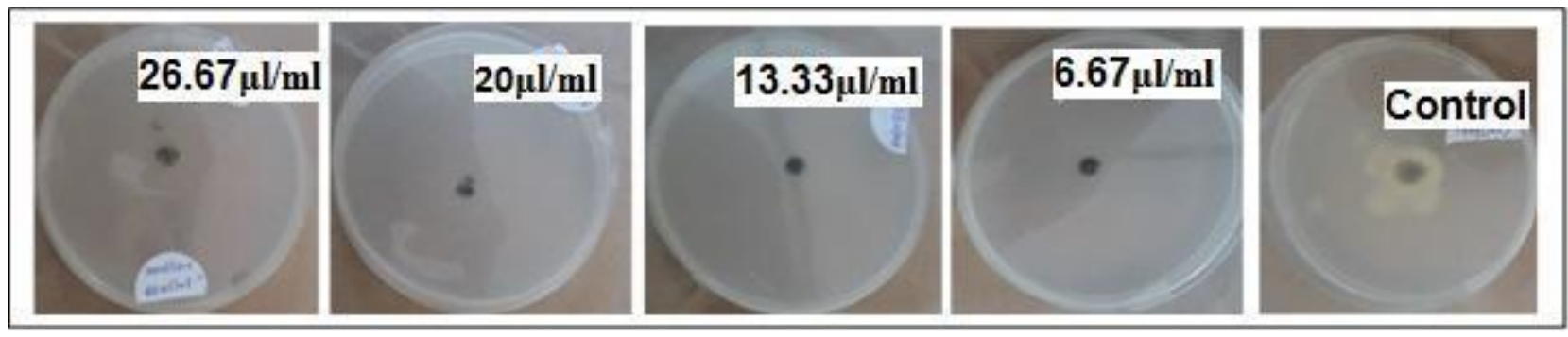

Fig. 4 - Amended PDA plates with varied concentration of Ocimum kilimandscharicum oil showing Aspergillus flavus colony.

Analysis of variance showed no significant difference of radial growth inhibition amongst the oil concentration level of $26.67,20,13.33$, and $6.67 \mu 1 / \mathrm{ml}$. The oil concentration level of $3.33 \mu \mathrm{l} / \mathrm{ml}$ resulted in $43 \%$ radial growth inhibition. Analysis showed a significant difference $(\mathrm{p}<0.0001)$ in the growth inhibitory effect between the $3.33 \mu \mathrm{l} / \mathrm{ml}$ concentration level and plain PDA (Table 1).

A significant difference $(\mathrm{p}<0.0001)$ in colony diameter of Aspergillus flavus was also observed between the days (day 1 , day 2, day 3, day 5 and day 7 ).

Furthermore, a significant interactive effect $(\mathrm{p}<0.0001)$ was observed between concentrations of the oil and days of colony diameter (Fig. 5).

Table 1 Mean colony diameter (in millimetres) of A. flavus on PDA amended with different concentration of $O$. kilimandscharicum oil

\begin{tabular}{ll}
\hline & Mean Colony diameter $(\mathbf{m m})$ \\
\hline Concentration $(\boldsymbol{\mu l} / \mathbf{m l})$ & $1.36 \pm 0.05^{\mathrm{a}}$ \\
Plain PDA (control) & $1.17 \pm 0.30^{\mathrm{b}}$ \\
3.33 & $0.79 \pm 0.001^{\mathrm{c}}$ \\
6.67 & $0.79 \pm 0.001^{\mathrm{c}}$ \\
13.33 & $0.79 \pm 0.001^{\mathrm{c}}$ \\
20 & $0.79 \pm 0.001^{\mathrm{c}}$ \\
26.67 & \\
\hline Days & $0.79 \pm 0.001^{\mathrm{d}}$ \\
Day 1 & $0.85 \pm 0.20^{\mathrm{c}}$ \\
Day 3 & $0.91 \pm 0.50^{\mathrm{b}}$ \\
Day 5 & $0.93 \pm 0.60^{\mathrm{a}}$ \\
Day 7 & \\
\hline P-values & 0.0001 \\
Concentration & 0.0001 \\
Day & 0.0001 \\
Concentration*Day & \\
\hline
\end{tabular}

Values expressed are means \pm SEM for four replicates. Means within respect columns accompanied by similar lower-case letters do not differ significantly at $\mathrm{P}<0.0001$

\section{Antifungal activity of Ocimum kilimandscharicum oil on Aspergillus flavus by disc diffusion}

Just as the agar disc diffusion method, similar radial inhibition pattern was observed using the 
disc diffusion method. Radial zones of inhibition recorded after 7 days for the different concentrations were as follows; $400 \mu \mathrm{l} / \mathrm{ml}$ (radial inhibition $=7.08 \mathrm{~mm}$ ), $300 \mu \mathrm{l} / \mathrm{ml}$ (radial inhibition $=6.53 \mathrm{~mm}), 200 \mu \mathrm{l} / \mathrm{ml}($ radial inhibition $=6.10 \mathrm{~mm}), 100 \mu \mathrm{l} / \mathrm{ml}($ radial inhibition $=5.93$ $\mathrm{mm}$ ) and $50 \mu \mathrm{l} / \mathrm{ml}$ (radial inhibition $=5.05 \mathrm{~mm}$ ).

Analysis of variance showed that a highest zone of inhibition $(\mathrm{p}<0.0001)$ occurred at concentration level of $400 \mu \mathrm{l} / \mathrm{ml}$. There was also a significant difference between the treatment concentrations and the control experiment $(\mathrm{p}<0.0001)$. Furthermore, there was a significant difference in the zone of inhibitions between the days of incubation (day1, day 3, day 5 and day 7).

A significant interactive effect $(\mathrm{p}<0.0001)$ was also observed between the concentrations of the oil and days on colony diameter (Fig. 6).

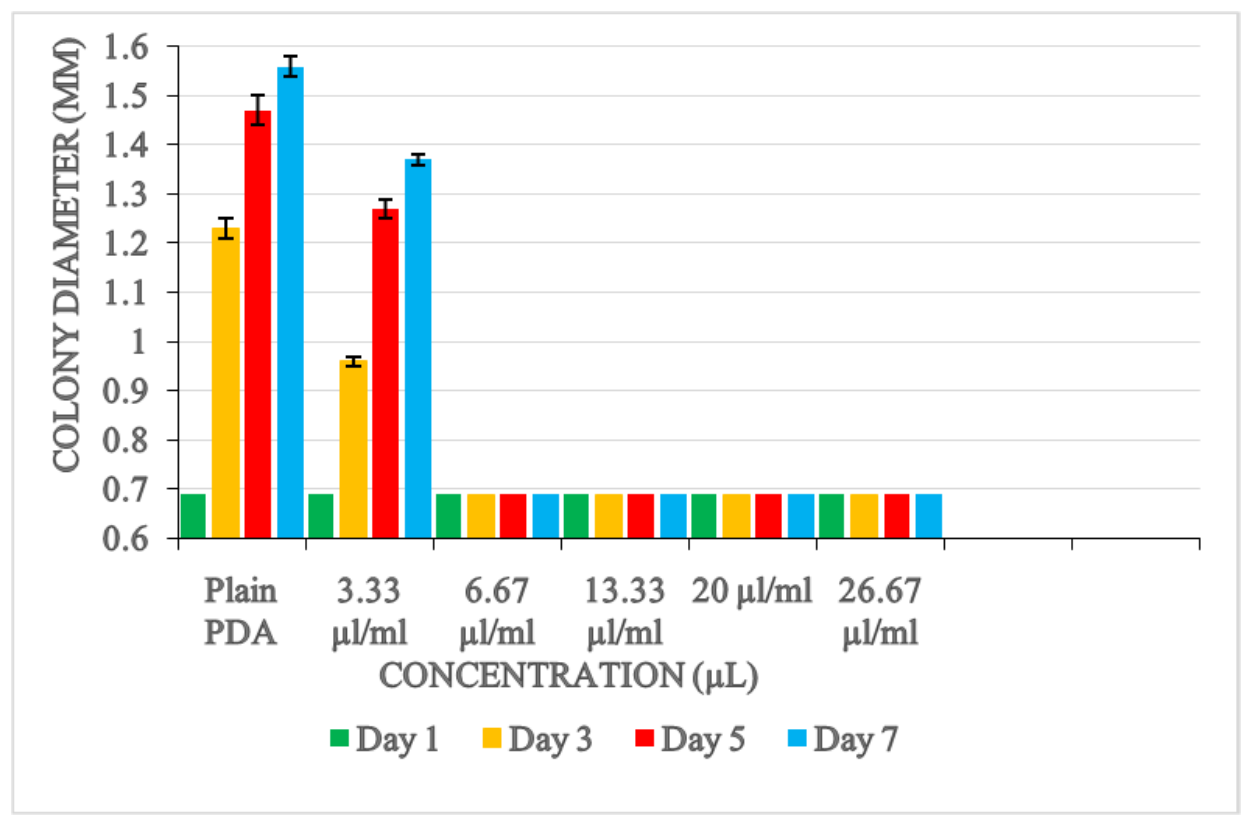

Fig. 5 - Interaction effects of concentration of Ocimum kilimandscharicum oil and days of incubation on colony diameter.

Table 2 Mean zone of inhibition (mm) of Aspergillus flavus culture grown on filter paper discs impregnated with Ocimum kilimandscharicum oil

\begin{tabular}{ll}
\hline & Size of zone of inhibition \\
\hline Concentration $(\boldsymbol{\mu l} / \mathbf{m l})$ & \\
Plain PDA (control) & $5.00 \pm 0.00^{\mathrm{f}}$ \\
50 & $5.06 \pm 0.01^{\mathrm{e}}$ \\
100 & $5.58 \pm 0.09^{\mathrm{d}}$ \\
200 & $5.76 \pm 0.12^{\mathrm{c}}$ \\
300 & $5.98 \pm 0.16^{\mathrm{b}}$ \\
400 & $6.34 \pm 0.22^{\mathrm{a}}$ \\
\hline Days & \\
Day 1 & $5.00 \pm 0.00^{\mathrm{c}}$ \\
Day 3 & $5.74 \pm 0.09^{\mathrm{b}}$ \\
Day 5 & $6.11 \pm 0.15^{\mathrm{a}}$ \\
Day 7 & $6.14 \pm 0.16^{\mathrm{a}}$ \\
\hline P-values & \\
Concentration & 0.0001 \\
Day & 0.0001 \\
Concentration*Day & 0.0001 \\
\hline
\end{tabular}

Values expressed are means \pm SEM for four replicates. Means within respect columns accompanied by similar lower-case letters do not differ significantly at $\mathrm{P}<0.0001$ by Tukey's HSD test. 


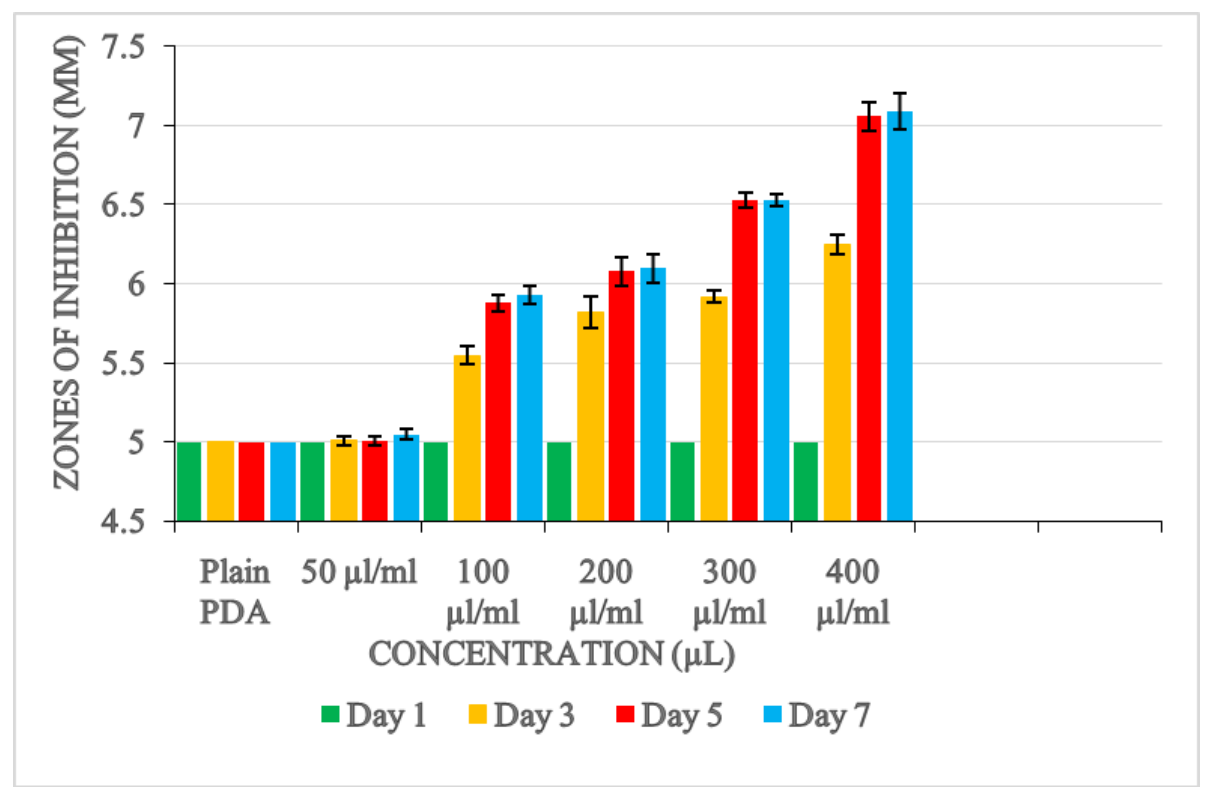

Fig. 6 - Interactive effects of concentration of Ocimum kilimandscharicum oil and days of incubation on size of zones of inhibition.

\section{Discussion}

\section{Pathogenicity test of Aspergillus flavus on maize}

The result indicated that Aspergillus flavus is capable of infecting maize grains as demonstrated by the colonization of the maize grains by the fungi, which eventually led to the complete rot of the grains. This observation therefore confirms that A. flavus is an important postharvest rot agent of maize. Studies by Kinyungu et al. (2019) identified A. flavus as one of the major fungal contaminants and mycotoxin producer on post-harvest maize. The presence of this fungi contributes to the loss in quality and quantity of the maize after harvest (Birgen et al. 2020). The loss in quality of the maize is reflected by its change in color due to the presence of the pigmentation of the fungus. Pigmentation of fungi is a typical characteristic of its growth (Lopes et al. 2019).

The fact that there was no growth on the control maize sample indicates that the maize were truly healthy from the onset of the experiment and thus had not been infected by any fungi. It further confirms that when healthy maize comes in contact with A. flavus it gets infected.

\section{Antifungal effect of Ocimum kilimandscharicum oil on growth of Aspergillus flavus using agar dilution method}

Result showed that the oils extracted from Ocimum kilimandscharicum exhibited antifungal effects on Aspergillus flavus. Using the agar disc diffusion method, complete inhibition of A. flavus growth was observed with concentrations $26,20,13.33$ and $6.66 \mu \mathrm{l} / \mathrm{ml}$. Concentration level of 3.33 $\mu \mathrm{l} / \mathrm{ml}$ showed a slight growth of A. flavus. In the control experiment (plain PDA), a rapid growth of A. flavus was observed. The fungal activity varied on the concentrations of the oil used. The antifungal effects were proportional to the concentrations of the oil extracts. Increase in level of concentration of the extracts enhanced the antifungal activity. The findings concur with similar reports done by Mares et al. (2004), Sharma \& Tripath (2007) who showed that growth inhibition levels increase with increase concentration of antimicrobials used.

\section{Antifungal effect of Ocimum kilimandscharicum oil on growth of Aspergillus flavus using disc diffusion method}

Variations in the growth inhibition of the fungi at different concentrations using the disc 
diffusion method was similar to that obtained from the agar disc diffusion method. Higher concentrations resulted in higher zones of inhibition. The $400 \mu \mathrm{l} / \mathrm{ml}$ concentration level had a significant highest zone of inhibition while the $50 \mu \mathrm{l} / \mathrm{ml}$ concentration level had the significant lowest inhibition zone compared with the control experiment (plain PDA). This further proves that the antifungal activity is proportional to the concentrations of the oil extracts. Increase in level of concentration of the extracts enhanced the antifungal activity.

Several evidences have been brought forth showing the existence of active compounds in plant materials. Studies by Eliningaya et al. (2009) showed that aqueous extracts of leaves of Ocimum kilimandscharicum contains active components such as camphene, 4-terpeneol, limonene, $\alpha$-terpineol, and linalool. These components have been shown to possess antimicrobial activities. Similar findings from Paschapur et al. (2009) also showed that leaves of O. kilimandscharicum contained biological active compounds such as triterpenoids saponins, tannins, sterols, flavonoids, carbohydrates and proteins. These compounds possess antimicrobial properties which protects the plants against infection by pathogens. Camphor has been shown to be one of the major components of O. kilimandscharicum oil (Sethi et al. 2012).

Other studies carried out by Gupta \& Saxena (2012) has shown that the essential oils from $O$. kilimandscharicum possess significant antifungal properties. Some of these oil exhibits various mechanisms of action. Reports by Rasooli \& Abyaneh (2004) showed that the use of thyme oil extracts brought about alterations in the morphology of species of Aspergillus parasiticus. These alterations included; hyphal distortion, sporulation failure, reduce conidiophore development, and loss of pigment.

Our present findings have shown inhibition of mycelia growth as one of the effects of $O$. kilimandscharicum oil on Aspergillus flavus. This inhibitory effect of the oil extracts may be as a result of natural bioactive chemicals found in the extracts (Rasooli \& Abyaneh 2004).

\section{Conclusions and Recommendations}

From the results, it can be concluded that $O$. kilimandscharicum oil acts against the Aspergillus flavus, and hence a potential source for developing a product that controls this fungus. It is desirable to encourage the communities where the plant grows to domesticate it, and to extract oil, for local use and possibly for export. This would create additional source of income, thus improving their livelihood. In addition, it is a natural product, hence environmentally safe, and can be made available by domesticating it resulting in an additional benefit of conserving biodiversity. Furthermore, it is also recommended that, the efficacy of the oil be tested on other post-harvest fungi.

\section{Acknowledgements}

Many thanks go to the farmers of Murang'a County for the provision of maize used throughout the research.

\section{Ethics declaration}

The research does not involve any studies dealing with humans and animals

\section{Conflict of interest}

No conflict of interest is declared by the authors in the publication of these findings.

\section{Consent for publication}

On behalf of the other authors, I (Corresponding Author) confirm that the manuscript has been read and is approved for submission

\section{References}

Akwa TE, Maingi JM, Birgen JK. 2020 - Susceptibility of Common Bean (Phaseolus Vulgaris L.) 
Cultivars Grown in Menoua Division, West Region of Cameroon to Storage Fungi Pathogens. Journal of Horticultural Science Research 3(1): 94-103. Doi 10.36959/745/404

Aryal S. 2015 - Potato Dextrose Agar (PDA); Principle, uses, composition, procedure and colony characteristics. Retrieved on February, 18, 2017.

Birgen JK, Cheruiyot RC, Akwa TE. 2020 - Mycotoxin Contamination of Stored Maize in Kenya and the Associated Fungi. Journal of Plant Pathology Research 2(1): 7-13.

Doi 10.36959/394/620

Dubey S, Suresh M, Singh B. 2007 - Evaluation of Trichoderma species against Fusarium oxysporum f. sp. Ciceris for integrated management of chickpea wilt. Biological Control. 40(1): 118-127.

Erkan N, Tao Z, Rupasinghe HV, Uysal B, Oksal BS. 2012 - Antibacterial activities of essential oils extracted from leaves of Murraya koenigii by solvent-free microwave extraction and hydro-distillation. Natural product communications, 7(1), $1934578 X 1200700139$.

Eliningaya JK, Hassan MN, Lucile L, Epiphania EK. 2009 - Efficacy of Ocimum kilimandscharicum plant extracts after four years of storage against Anopheles gambiaess. Journal of Cell and Animal Biology. 3: 171-174.

Farrell T, O'Keefe K. 2007 - Maize. NSW Department of Primary Industries.

Gupta N, Saxena G. 2010 - Antimicrobial activity of constituents identified in the essential oils from Ocimum kilimandscharicum Mentha and Cinnamomum through GC-MS. International Journal Biological Sciences. 1(4): 715-720.

Kinyungu S, Isakeit T, Ojiambo PS, Woloshuk CP. 2019 - Spread of Aspergillus flavus and aflatoxin accumulation in postharvested maize treated with biocontrol products. Journal of Stored Products Research, 84, 101519.

Klich MA. 2002 - Identification of common Aspergillus Species. Centraal bureau voor schimmecultures, Utrecht, Netherlands.

Kumar R, Mishra AK, Dubey NK, Tripathi YB. 2007 - Evaluation of Chenopodium ambrosioides oil as a potential source of antifungal, antiaflatoxigenic and antioxidant activity. International Journal of Food Microbiology. 115 (2): 159-164.

Lopes FC, Tichota DM, Pereira JQ, Segalin J. 2013 - Pigment production by filamentous fungi on agro-industrial byproducts: an eco-friendly alternative. Applied biochemistry and biotechnology, 171(3), 616-625.

Mares D, Tosi B, Poli F, Andreotti E, Romangnoli C. 2004 - Antifungal activity of Tagetus patula on some phytopatoghenic fungi ultrastructural evidence on Phythum ultimum. Microbiology Research. 859: 295-304.

Mutahi SK. 2010 - A study to investigate the use of agricultural research as a tool for poverty reduction in Muranga County (Doctoral dissertation).

Bansod S, Rai M. 2008 - Antifungal activity of essential oils from Indian medicinal plants against human pathogenic Aspergillus fumigatus and A. niger. World Journal of Medical Sciences, $3(2), 81-88$.

Ndagi JM. 2017 - Monitoring and evaluation practices, ethics and sustainability of agricultural food crop projects in Nyeri County, Kenya (Doctoral dissertation, University of Nairobi).

Nikolić M, Savić I, Stanković S. 2016 - Pathogenicity of Aspergillus spp. isolates originating from Serbia. Ratarstvo i povrtarstvo, 53(3), 101-105.

Paschapur MS, Patil MB, Ravi K, Sachin RP. 2009 - Evaluation of aqueous extract of leaves of Ocimum kilimandscharicum on wound healing activity in albino wistar rats. International Journal of Pharmtech Research Coden. 1: 544-550.

Rasooli I, Abyaneh MR. 2004 - Inhibitory effects of thyme oils on growth and aflatoxin production by Aspergillus parasiticus. Food Control. 15: 479-483.

Samson RA, Houbraken J, Thrane U, Frisvad JC, Andersen B. 2010 - Food and indoor fungi.

Schulz B, Wanke U, Draeger S, Aust HJ. 1993 - Endophytes from herbaceous plants and shrubs: effectiveness of surface sterilization methods. Mycological research, 97(12), 1447-1450. 
Sharma N, Tripath A. 2007 - Effects of Citrus (L.) Osbeck epicarp essential oil on growth and morphogenesis of Aspergillus niger (L.) Van Tieghem. Microbiology Research. 163(3): 337344.

Sethi S, Chandra M, Prakash O, Pant AK. 2012 - Phytochemical analysis and in vitro antioxidant activity of essential oils and methanolic extracts of Ocimum spp. (Indian Basils) growing in uttarakhand region of Central Himalayas, in traditional and folk herbal medicine, vol 1 (New delhi) 365-389. 